\title{
Is sclerosant injection mandatory after an epinephrine injection for arrest of peptic ulcer haemorrhage? A prospective, randomised, comparative study
}

\author{
Hwai-Jeng Lin, Chin-Lin Perng, Shou-Dong Lee
}

\begin{abstract}
A prospective, randomised, comparative study was performed to assess the need for a pure alcohol injection after an epinephrine injection in the arrest of active peptic ulcer bleeding. Sixty four patients with active ulcer bleeding were enrolled in the study. The two groups (epinephrine and epinephrine plus pure alcohol) were matched for sex, age, site of bleed, endoscopic findings, shock, haemoglobin, and concomitant illness at randomisation. The volume of injected epinephrine in the epinephrine and the epinephrine plus pure alcohol groups mean (SD) was 6.0 (3.0) $\mathrm{ml}$ and $5.5(3.0) \mathrm{ml}$ respectively $(\mathrm{p}>0.05)$. The volume of injected pure alcohol in the epinephrine plus pure alcohol group was $1.9(1.1) \mathrm{ml}$. Bleeding was initially controlled in $31(97 \%)$ of the epinephrine group and all of the epinephrine plus pure alcohol group. Rebleeding occurred in $11(36 \%)$ of the epinephrine group and in five $(16 \%)$ of the epinephrine plus pure alcohol group ( $p>0.05)$. Rebleeding was successfully controlled in some patients with treatment by a second injection. Other patients had heat probe thermocoagulation or surgery. Ultimate haemostatic rates were $69 \%(22 / 32)$ and $88 \%$ $(28 / 32)$ for the epinephrine and the epinephrine plus pure alcohol groups respectively ( $>00.05)$. The epinephrine plus pure alcohol group achieved a better haemostatic effect for spurting haemorrhage $(9 / 10 v 5 / 11, \mathrm{p}<0.05)$. The need for emergency operations and blood transfusions were comparable in both groups. The stay in hospital were less in the epinephrine plus pure alcohol group (mean $4.3 \mathrm{v} 7 \cdot 1$, $\mathbf{p}<\mathbf{0 . 0 5}$ ). It is concluded that pure alcohol injection after an epinephrine injection can improve the haemostatic rate in patients with spurting haemorrhage and shorten the hospital stay for patients with active ulcer bleeding. (Gut 1993; 34: 1182-1185)
\end{abstract}

Division of

Gastroenterology,

Department of Medicine, Veterans General

Hospital, Taipei,

Taiwan, Republic of

China

H-J Lin

C-L Perng

S-D Lee

Correspondence to:

Dr Hwai-Jeng Lin,

Division of Gastroenterology,

Department of Medicine,

Veterans General Hospital,

Taipei, Taiwan 11217

Republic of China.

Accepted for publication

5 January 1993

The death rate for bleeding peptic ulcers has averaged between $6 \%$ and $10 \%$ over the past 30 years. ${ }^{1-4}$ It occurs almost exclusively in patients over 60 years as a result of the postoperative complications of surgery performed for continued or recurrent bleeding.

Although various endoscopic treatments have been developed in the past 10 years, heat probe thermocoagulation and multipolar electrocoagulation are the two most promising techniques for treating bleeding peptic ulcers. ${ }^{1}$ Endoscopic injection, however, is still the most convenient and cost effective means for the arrest of peptic ulcer haemorrhage. ${ }^{6-8}$ In two prospective, randomised trials, endoscopic injection and multipolar electrocoagulation are concluded to be equally effective in the arrest of massive peptic ulcer bleeding. ${ }^{910}$ Further study of endoscopic injection is needed.'

Among the various solutions, epinephrine and pure alcohol are proved to be effective in the arrest of peptic ulcer haemorrhage. ${ }^{8911-16}$ Controversy still exists concerning the need of sclerosing agents injection after epinephrine injection. Some authors supported combined use of both agents with good results, ${ }^{17-22}$ while others found that a sclerosing agent does not improve haemostatic rates. ${ }^{13}$

The purpose of this article is to evaluate if a pure alcohol injection is required after an epinephrine injection to arrest peptic ulcer haemorrhage.

\section{Patients and methods}

Patients were accepted for endoscopic injection if an active bleeder (spurter or oozer) was seen during an emergency endoscopic examination after resuscitation. The possibility of complications of endoscopic injection were discussed with the patients or their relatives, or both and written informed consent was obtained before the trial.

All haemostatic treatments were performed by Lin and Perng who had experience of at least 5000 cases in endoscopic examination and experience of 300 cases in treatment with endoscopy.

Patients were excluded from the study if (1) they were unable or unwilling to give written informed consent, (2) had bleeding tendency (platelet count $\leq 50000 / \mathrm{mm}^{3}$, prothrombin time less than $30 \%$, or taking anticoagulants), (3) had a non-bleeding visible vessel, (4) had a bleeding gastric cancer, or (5) had more than one bleeding source.

For every patient enrolled in the study, a sealed envelope was opened before performing an endoscopic injection to decide the injected solution. Two forms of injection were arranged by a statistician who was not involved in the study. The study was approved by Clinical Hospital, Taipei, Republic of China.

We used an Olympus GIF P-10 or PQ-20 end view endoscope and an NM-8L injector to perform endoscopic injection. The following solutions were used for endoscopic injection: for Research Committee in the Veterans General 
the epinephrine group, we injected $0.5-1 \cdot 0 \mathrm{ml}$ of $1: 10000$ epinephrine at $2-3 \mathrm{~mm}$ around the bleeder with a maximum volume of $15 \mathrm{ml}$; for the epinephrine plus pure alcohol group, we injected the same volume of 1:10000 epinephrine followed by $0.3-0.5 \mathrm{ml}$ of alcohol $(99.8 \%)$ around the bleeder with maximal volume of $3 \mathrm{ml}$. Failure was defined for patients who could not obtain initial haemostasis with the above injected volume. For those, we tried heater probe thermocoagulation or surgical intervention.

Rebleeding was suspected if we found fresh blood in the stomach six hours after entry into the study, presence of unstable vital signs and continued tarry, bloody stools or haematemesis. For these patients, we performed an emergency endoscopy. If active bleeding or a fresh blood clot was found at the ulcer base, rebleeding was confirmed.

For ethical reasons, treatment regimens were discussed with patients who rebled. They might receive a second injection with the same solution or other solutions, heater probe thermocoagulation or surgery.

The vital signs of the patients were checked every hour for the first 12 hours, every two hours for the second 12 hours, and every four hours for the following 24 hours until they became stable, and then four times daily. A nasogastric tube was inserted and maintained until 24 hours after treatment. The haemoglobin and packed cell volume were checked at least once daily, and a blood transfusion was given if the haemoglobin dropped to less than $9 \mathrm{~g} / \mathrm{dl}$ or if the vital signs deteriorated. $\mathrm{H}_{2}$ blockers (ranitidine $100 \mathrm{mg}$ or cimetidine $400 \mathrm{mg}$ intravenously every 12 hours) were given routinely. The physicians or surgeons were made aware of the exact endoscopic findings and treatment given in each case. Endoscopy was followed 72 hours later. If no blood clot or haemorrhage was seen in the ulcer base, the patient was discharged and followed up with an endoscopy on the seventh day, the first month, and every month until scarring of the lesion ensued. $\mathrm{H}_{2}$ blockers (ranitidine $150 \mathrm{mg}$ or cimetidine $400 \mathrm{mg}$ twice daily) were given orally to every patient for at least two months at the outpatient department.

Shock was defined as systolic pressure less than $100 \mathrm{~mm} \mathrm{Hg}$ and pulse rate greater than 100 beats/min accompanied by cold sweating, pallor, and oliguria. Initial haemostasis was defined as no haemorrhage persisting for five minutes after injection. Ultimate haemostasis was defined as lack of rebleeding for $\mathbf{3 0}$ days after treatment.

We used Student's $t$ test to compare the basic data of age, volume of blood transfusion, haemoglobin, and length of hospital stay; $\chi^{2}$ test with or without Yates's correction and Fisher's exact test when appropriate to compare the haemostatic effects among the two groups of patients. A probability value of less than 0.05 was considered significant.

\section{Results}

Between December 1990 and May 1992, a total of 1520 patients whose main complaint was haematemesis or tarry stools, or both attended the emergency department. A total of 1240 patients had an emergency endoscopic examination within 12 hours of arrival at the emergency department. Eight hundred and ninety eight patients had peptic ulcers. We failed to identify a source of bleeding in 40 patients. Peptic ulcers with bleeding (oozing or spurting) were found in 100 patients. A total of 36 cases were excluded from the study: 20 patients refused to give informed consent, eight had bleeding gastric cancers, and eight had a bleeding tendency. There were 64 patients enrolled in the study, 32 patients in each group. The two groups were well matched for factors affecting outcome (Table I).

For the epinephrine group, we found visible vessels in 23 cases ( 15 cases with oozing, eight cases with spurting). For the epinephrine plus pure alcohol group, we found visible vessels in 21 cases (14 cases with oozing, seven cases with spurting).

Table II shows the clinical outcome of the patients studied. In the epinephrine group, patients received a mean volume of $6.0 \mathrm{ml}$ of 1:10000 epinephrine, while the epinephrine plus pure alcohol group received a mean volume of

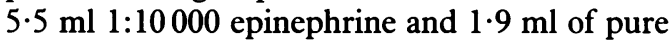
alcohol. Both groups received a similar volume of blood transfusion. We failed to achieve initial haemostasis in one patient $(3 \%)$ of the epinephrine group, and none of the epinephrine plus pure alcohol group $(p>0.05)$. A rebleeding episode occurred in 11 patients $(36 \%)$ of the epinephrine group, and five patients $(16 \%)$ of the epinephrine plus pure alcohol group $(\mathrm{p}>0.05)$.

In the epinephrine group, the only case who failed to achieve initial haemostasis received surgical intervention. Spurting haemorrhage was seen during operation. Of 11 rebleeders, three received a second epinephrine injection and two of them achieved haemostasis (the failed case had successful surgical intervention); six received epinephrine injection followed by pure alcohol injection and all achieved haemostasis; two received surgical intervention directly (one emergency operation because of massive bleeding and one elective operation because of adenocarcinoma of the stomach as well as a bleeding duodenal ulcer).

For the epinephrine plus pure alcohol group, all achieved initial haemostasis. Of the five rebleeders, two received a second injection with the same solution and one achieved haemostasis, the other refused an operation and died soon

TABLE I Clinical variables of patients receiving endoscopic injection

\begin{tabular}{lll}
\hline & $E P I(n=32)$ & $E P I+P A(n=32)$ \\
\hline Sex $(M / F)$ & $30 / 2$ & $27 / 5$ \\
Age $(y)$ & $60 \cdot 8(16 \cdot 2)$ & $58 \cdot 5(15 \cdot 5)^{\star}$ \\
Location of bleeders & & \\
$\quad$ Stomach & 10 & 8 \\
Body & 3 & 8 \\
$\quad$ Antrum & 18 & 16 \\
$\quad$ Duodenum & 1 & 0 \\
Stoma & 11 & 10 \\
Endoscopic findings & 21 & 22 \\
$\quad$ Spurting & 13 & 13 \\
$\quad$ Oozing & $9 \cdot 4(2 \cdot 9)$ & $9 \cdot 9(2 \cdot 6)^{\star}$ \\
Shock & 10 & 9 \\
Initial haemoglobin &
\end{tabular}

^Mean (SD); EPI: epinephrine, PA: pure alcohol. No statistical significance was seen in all clinical variables between the two groups. 
TABLE II Results of the patients with peptic ulcer haemorrhage receiving an endoscopic injection

\begin{tabular}{lccl}
\hline & $E P I(n=32)$ & $E P I+P A(n=32)$ & $p$ Value \\
\hline Vol of injected EPI solution $(\mathrm{ml})$ & $6 \cdot 0(3 \cdot 0)^{\star}$ & $5 \cdot 5(3 \cdot 0)$ & $\mathrm{NS}$ \\
Vol of injected PA (ml) & $1200(1100)$ & $1200(1600)$ & $\mathrm{NS}$ \\
Vol of blood transfusion $(\mathrm{ml})$ & $31(97 \%)$ & $32(100 \%)$ & $\mathrm{NS}$ \\
No achieving initial haemostasis & $11 / 31(36 \%)$ & $5 / 32(16 \%)$ & $\mathrm{NS}$ \\
No rebleeding & $22 / 32(69 \%)$ & $28 / 32(88 \%)$ & $\mathrm{NS}$ \\
No achieving ultimate haemostasis & $5 / 11(46 \%)$ & $9 / 10(90 \%)$ & $\mathrm{p}<0 \cdot 05$ \\
Spurting & $17 / 21(81 \%)$ & $19 / 22(86 \%)$ & $\mathrm{NS}$ \\
Oozing & 1 & 2 & $\mathrm{p}<0 \cdot 05$ \\
No with emergency operations & $7 \cdot 1(5 \cdot 2)$ & $4 \cdot 3(3 \cdot 2)$ & $\mathrm{NS}$ \\
Stay in hospital (days) & 0 & 2 & \\
No of deaths & & & \\
\hline
\end{tabular}

${ }^{\star}$ Mean (SD); EPI: epinephrine; PA: pure alcohol.

afterwards; one received heater probe thermocoagulation and achieved haemostasis; and two received surgical intervention (one of them died of wound infection with sepsis, the other had an uneventful course).

Rebleeding occurred within three days in eight $(78 \%)$ of the epinephrine group and three $(60 \%)$ of the epinephrine plus pure alcohol group. No complications of perforation or aspiration could be seen in both groups.

Finally, we achieved ultimate haemostatic rates of $69 \%(22 / 32)$, and $88 \%(28 / 32)$ in the epinephrine and the epinephrine plus pure alcohol groups respectively ( $p>0 \cdot 05)$. For spurting bleeders, we achieved a significantly better haemostatic rate in the epinephrine plus pure alcohol group $(9 / 10 v 5 / 11, \mathrm{p}<0.05)$.

The stay in hospital was significantly shorter in the epinephrine plus pure alcohol group (mean $4.3 \vee 7.1, \mathrm{p}<0.05$ ). The number of emergency operations because of bleeding and the number of patients who died were comparable in both groups.

\section{Discussion}

Death from peptic ulcer haemorrhage can be lowered with better hospital care including combined medical and surgical teams and the latest endoscopic treatment. ${ }^{23}$ Recent attention has focused on endoscopic injection with encouraging results. ${ }^{61113151921}$ There are, however, only a few controlled trials. ${ }^{11} 13181921$

Patients with peptic ulcer and spurting haemorrhage have an $85 \%$ incidence of further haemorrhage and a death rate of $50 \% .{ }^{24}{ }^{25}$ They usually need surgery or endoscopy treatment. Peptic ulcer patients with oozing haemorrhage have a death rate of $13 \cdot 3 \%$ - four to five times that of patients whose ulcers have a clean base. ${ }^{24}$ We have proved that endoscopy treatment can improve haemostatic rate in patients with active ulcer bleeding. ${ }^{11}$ Therefore, we enrolled patients with spurting or oozing haemorrhage in this comparative trial.

Most episodes of haemorrhage from peptic ulcers should be controlled at first without surgery. A skilled endoscopist is essential, but the equipment can be as simple as a standard endoscope and an injection needle. ${ }^{26}$ In this study, all endoscopic injections were performed by two endoscopists who had at least five years' experience of endoscopic examination and one year's experience of endoscopic injection. The ultimate success rate and rebleeding rate of these two endoscopists were comparable.

It is difficult to determine the most effective and safest solution for the arrest of peptic ulcer haemorrhage because of the wide variation in results from different investigators and the lack of comparative or controlled trials. ${ }^{27}$

Epinephrine or pure alcohol was commonly used as the solution for injection for the arrest of peptic ulcer haemorrhage in the past 10 years. ${ }^{11-14161921}$ The primary mechanism of arterial haemostasis for epinephrine is compression of the artery in the serosal space. It is also associated with severe focal mucosal damage but no thrombi are found in the submucosal vessels. Therefore, significant bleeding cannot be arrested with epinephrine alone. ${ }^{27} 28$ Pure alcohol, by in situ tissue fixation and arterial compression, which causes arterial coagulation and tissue injury, is proved to be the most efficacious sclerosing agent in the arrest of arterial bleeding. ${ }^{27} 28$ Epinephrine can localise the sclerosant to the injected area, and maximise its effect. ${ }^{19}$ The combination of both agents may be superior to either one.

Rebleeding is the most important predictor for death from bleeding ulcer. ${ }^{29}$ Although epinephrine was effective in achieving initial haemostasis $(97 \%)$ in our series, the rebleeding rate was high $(11 / 31,36 \%)$. This is higher than that reported by Leung et al. ${ }^{14}$ Pure alcohol injection after an epinephrine injection tended to decrease the rebleeding rate in our series. It is possible that epinephrine can only temporarily stop bleeding and keep vessel existent, while a sclerosing agent can actually clot the vessel, and thereby decrease rebleeding. ${ }^{27} 28$

Because of ethical reasons, not all rebleeders in both groups received a second injection with the same solution. Rebleeders who did not receive a second injection with the same solution were defined as failed cases. Therefore, the ultimate haemostatic rate may be higher if they all received the same injection again.

Nine rebleeders of the epinephrine group received a second injection (three cases) or epinephrine plus pure alcohol (six cases) and eight achieved ultimate haemostasis. This may explain the low number of emergency operations and death in the epinephrine group.

We conclude that epinephrine could achieve a high initial haemostatic rate. The rebleeding rate was high, however, and this could be decreased with pure alcohol injection after the epinephrine injection. The stay in hospital could be shortened for patients as well. For patients with spurting peptic ulcers, we suggest pure alcohol injection after an epinephrine injection instead of epinephrine injection alone.

We thank Dr Fa-Yauh Lee for his suggestions for this manuscript

$1 \mathrm{NIH}$ consensus conference on therapeutic endoscopy and bleeding ulcers. FAMA 1989; 262: 1369-72.

2 Silverstein FE, Gilbert DA, Tedesco FJ, Buenger NK, Persing J. The National ASGE survey on upper gastroPersing J. The National ASGE survey on upper gastr

3 Fleischer D. Etiology and prevalence of severe persistence upper gastrointestinal bleeding. Gastroenterology 1983; 84:
$538-43$.

4 Silverstein FE, Feld AD, Gilbert DA. Upper gastrointestinal tract bleeding. Arch Intern Med 1981; 41: 322-7.

5 Dronfield MW. Medical or surgical management for haematemesis or melaena. $\mathcal{F} R$ Coll Physicians Lond 1979 13: $84-6$. 
6 Sanowski RA, Waring JP. Endoscopic injection therapy for nonvariceal bleeding lesions of the upper gastrointestinal tract. $\mathcal{F}$ Clin Gastroenterol 1989; 11: 247-52.

7 Lin HJ, Chan CY, Lee FY, Huang ZC, Lee CH, Lee SD. Endoscopic injection to arrest peptic ulcer hemorrhage: a prospective, randomized controlled trial; preliminary results. Hepatogastroenterology 1991; 38: 291-4

8 Balanzo J, Villanueva C, Sainz S, Espinos JC, Mendez C, Guarner $\mathrm{C}$, et al. Injection therapy of bleeding peptic ulcer. A prospective, randomized trial using epinephrine and thrombin. Endoscopy 1990; 22: 157-9.

9 Laine L. Multipolar electrocoagulation versus injection therapy in the treatment of bleeding peptic ulcers. Gastrotherapy in the treatment of

10 Waring JP, Sanowski RA, Sawyer RL, Woods CA, Foutch PG. A randomized comparison of multipolar electrocoagulation and injection sclerosis for the treatment of bleeding peptic ulcer. Gastrointest Endosc 1991; 37: 295-8.

11 Lin HJ, Lee FY, Kang WM, Tsai YT, Lee SD, Lee CH. Heat probe thermocoagulation and pure alcohol injection in massive peptic ulcer haemorrhage: a prospective, randomized controlled trial. Gut 1990; 31: 753-7.

12 Lin HJ, Tsai YT, Lee SD, Lai KH, Lee FY, Lin CY, et al. A prospectively randomized trial of heat probe thermocoagulation versus pure alcohol injection in nonvariceal peptic ulcer hemorrhage. Am F Gastroenterol 1988; 83: 283-6.

13 Chung SCS, Leong HT, Chan ACW, Yung MY, Leung JWC, $\mathrm{Li}$ AKC. Epinephrine or epinephrine plus alcohol for injection of bleeding ulcers? Gastroenterology 1992; 102: A275.

14 Chung SCS, Leung JWC, Steele RJC, Crofts TJ, Li AKC. Endoscopic injection of adrenalin for actively bleeding Endoscopic injection of adrenalin for actively
ulcers: a randomised trial. $B M \mathcal{F} 1988 ; 296: 1631-3$.

15 Pascu O, Draghici A, Acalovchi I. The effect of endoscopic haemostasis with alcohol on the mortality rate of nonvariceal upper gastrointestinal hemorrhage. A randomized prospective study. Endoscopy 1989; 21: 53-5.

16 Sugawa C, Fujita Y, Ikeda T, Walt AJ. Endoscopic haemostasis of bleeding of the upper gastrointestinal tract by local injection of ninety-eight per cent dehydrated ethanol. Surg Gynecol Obstet 1986; 162: 159-63.
17 Soehendra N, Grimm H, Stenzel M. Injection of nonvaricea bleeding lesions of the upper gastrointestinal tract. Endoscopy 1985; 17: 129-32.

18 Panés J, Viver J, Forné M, Garcia-Olivares E, Marco C, Garau . Controlled trial of endoscopic sclerosis in bleeding peptic ulcers. Lancet 1987; ii: 1292-4.

19 Rajgopal C, Palmer KR. Endoscopic injection sclerosis: effective treatment for bleeding peptic ulcer. Gut 1991; 32: $727-9$

20 Di Felices G. Endoscopic injection treatment in patients with shock and gastrointestinal bleeding or stigmata of recent hemorrhage. Endoscopy 1987; 19: 185-9.

21 Rutgeerts P, Vantrappen G, Broeckaert L, Cormans G Janssens J, Hiele M. Comparison of endoscopic polidocanol injection and YAG laser therapy for bleeding peptic ulcers. Lancet 1989; i: 1164-6.

22 Kortan P, Haber G, Marcon N. Endoscopic injection therapy for nonvariceal bleeding lesions of the upper gastrointestina tract. Gastrointest Endosc 1986; 32: A145.

23 Steele RJC. Endoscopic haemostasis for non-variceal upper gastrointestinal haemorrhage. Br $\mathcal{F}$ Surg 1989; 76: 219-25.

24 Pimpl W, Boeckl O, Waclawiczek HW, Heinerman M. Estimation of the mortality rate of patients with severe Estimation of the mortality rate of patients with severe
gastroduodenal hemorrhage with the aid of new scoring gastroduodenal hemorrhage with

25 Storey DW, Bown SG, Swain CP, et al. Endoscopic prediction of recurrent bleeding in peptic ulcers. $N$ Engl f Med 1981 305: 915-6.

26 Bown S. Bleeding peptic ulcers. BMF 1991; 302: 1417-8

27 Randall GM, Jensen DM, Hirabayashi K, Machicado GA. Controlled study of different sclerosing agents for coagula-
tion of canine gut arteries. Gastroenterology 1989; 96: 1274-81.

28 Rutgeerts P, Geboes K, Vantrappen G. Tissue damage produced by hemostatic injections. Gastrointest Endosc 1986 32: A179.

29 Avery-Jones F. Haematemesis and melena with special reference to causation and the factors influencing mortality from bleeding peptic ulcer. Gastroenterology 1956; 30 166-90. 